\title{
Dispersal of Oxyops vitiosa: A Biological Control Agent of Melaleuca in Florida 1
}

\author{
William A. Overholt and Paul D. Pratt ${ }^{2}$
}

\section{Introduction}

\section{Melaleuca, Melaleuca quinquenervia}

(Myrtaceae), is an Australian woody tree introduced into Florida in the late 1800s and early 1900s as an ornamental and for erosion control (Figure 1). Later, seeds were dispersed from airplanes to drain the everglades. Melaleuca is well-adapted to moist open habitats, and has now colonized as much as 494,000 acres in the state, most notably large areas of sawgrass marsh in the Everglades. In a suitable wetland habitat, melaleuca can reach densities of up to 53,000 trees per acre, and form nearly impenetrable thickets. Scientists estimate the rate of spread since its introduction to be over 7000 acres per year. The harmful effects of melaleuca to Florida include loss of land for recreation, and negative impacts on native vegetation and wildlife. Between 1989 and 1999, public agencies in Florida spent $\$ 25$ million to control melaleuca, and they estimate its economic impact on recreation, tourism fires and loss of endangered species to be as much as $\$ 2$ billion over a period of 20 years.

In 1986, USDA/ARS scientists at the Invasive Plant Research Laboratory in Fort Lauderdale started

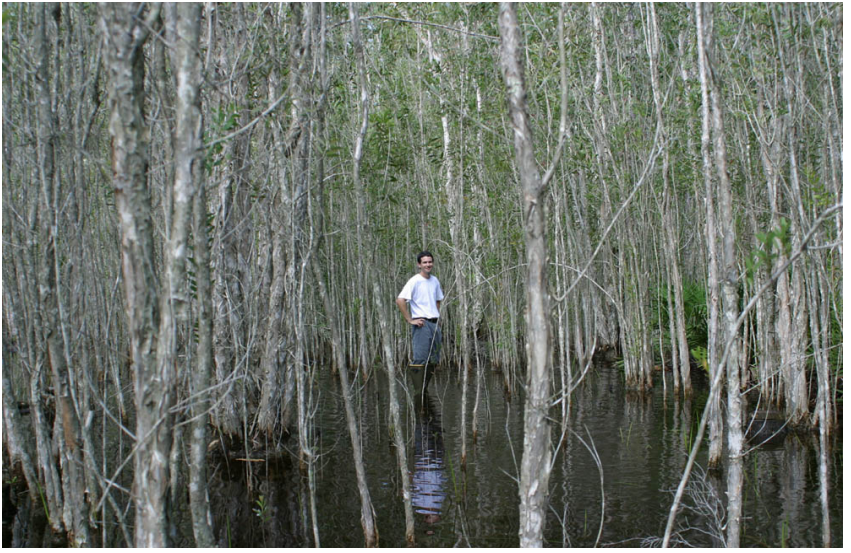

Figure 1. Melaleuca stand in the Florida Everglades.

a classical biological control program against melaleuca. The scientists recently released two insects as part of that program; the melaleuca weevil (Oxyops vitiosa (Coleoptera: Curculionidae)) and the melaleuca psyllid (Boreioglycapsis melaleucae (Hemiptera: Psyllidae)). This publication discusses the current distribution and dispersal rate of the weevil since in its introduction.

\section{Distribution of Melaleuca}

Melaleuca occurs primarily south of the northern edge of Lake Okeechobee, although smaller

1. This document is ENY-701, one of a series of the Entomology and Nematology Department, Florida Cooperative Extension Service, Institute of Food and Agricultural Sciences, University of Florida. Publication date: March 2004. Please visit the EDIS website at http://edis.ifas.ufl.edu.

2. William A. Overholt, assistant professor, Indian River Research and Education Center, University of Florida, Fort Pierce, FL, and Paul D. Pratt, research entomologist, Invasive Plant Research Laboratory, USDA/ARS, Fort Lauderdale, FL 
populations occur further north. Scientists estimated the distribution of melaleuca in the southern part of the state using aerial and ground surveys and satellite imagery.

The results of these surveys show melaleuca concentrations along the east and west coasts (Figure 2 ), reflecting the early history of introduction into these two areas.

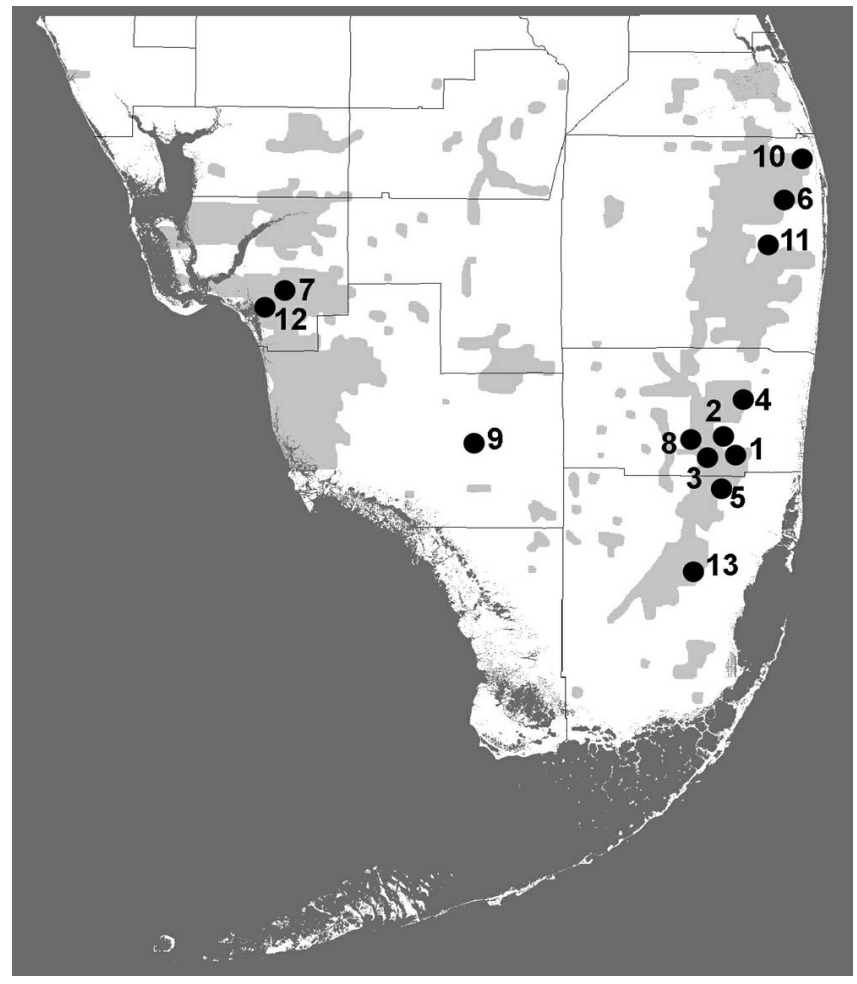

Figure 2. Distribution of melaleuca in south Florida (gray) and weevil release sites (black dots).

\section{Melaleuca Weevil}

Melaleuca weevils are small, grey and 6 to 9 millimeters long (Figure 3). Both adults and larvae are host specific, and feed on the young foliage of melaleuca trees. Adults can live a year or more, and females lay up to 9 eggs per day. The larvae produce a yellow, oily secretion that covers their bodies, and offers protection from predators. Older larvae appear black, as fecal matter collects in the oily secretion. The fecal matter appears as a long, thin coil attached to the larva (Figure 4). Research also shows that a density of 0.5 weevils per growing tip significantly decreases growth and development of melaleuca.

In the spring of 1997, scientists released the weevil at 13 locations in the infested area (Figure 2).

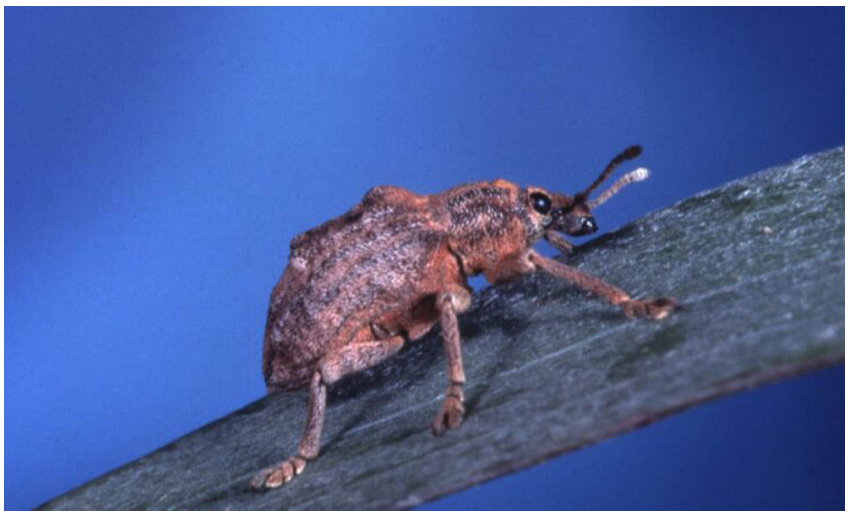

Figure 3. Adult melaleuca weevil.

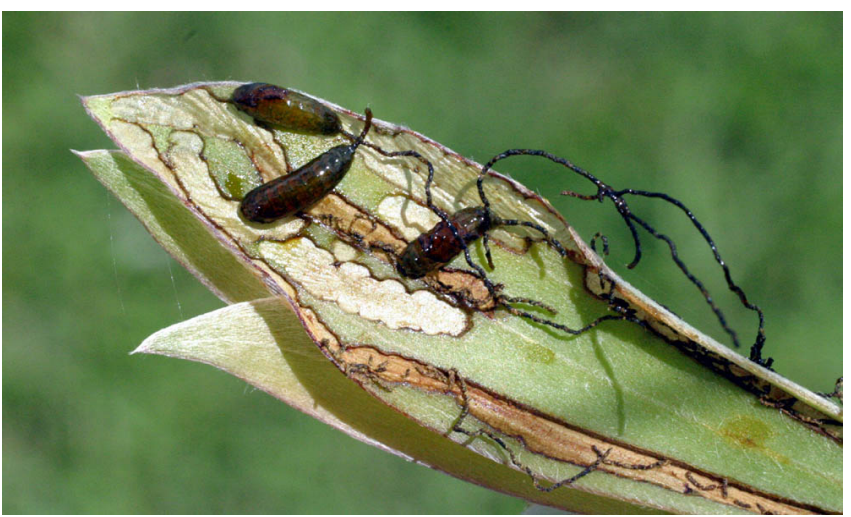

Figure 4. Larvae of melaleuca weevil with fecal coil.

The scientists monitored the weevils spread from these sites from the time of release until 2001, and also characterized the sites by the density of melaleuca per acre, the number of weevils released, number of months during which the ground was inundated with water, predominant wind direction, and time since release. Overall, the weevils moved an average of 0.61 miles per year, with a range of 0.06 (112 yards) to 1.8 miles per year. This is very slow compared to most other newly-released biological control agents. The tree density, time after release, and the number of weevils released influenced the rate of dispersal. The denser the stand of melaleuca, the slower the rate of spread. Also, as may be expected, the greater the amount of time since the release, the farther the insects traveled, and the more insects that were released, the faster they dispersed.

\section{Predicted Spread}

In 2001, it was estimated that the weevils occupied 1568 acres at the economic threshold of 0.5 weevils per growing tip, and 20,792 acres had weevils at a detectable density of one weevil per 1000 
tips. Assuming no further human-assisted

distribution, and a medium level of tree density, the scientists predict that $50 \%$ of the area occupied by melaleuca will have weevil densities of 0.5 weevils per tip or greater by June 2008. Assuming denser stands, it may take until 2012 to reach $50 \%$ of the area with 0.5 weevils per tip or greater. However, additional releases at new sites can reduce the amount of time it takes for the weevils to reach all melaleuca infested areas. Thus, releases are currently being made at many locations in several counties in southern Florida. If you are interested in releasing weevils on your land, you can contact Mr. Ken Gioeli at the St. Lucie County Extension Office (see http://kgioeli.ifas.ufl.edu/biocontrolorder.htm).

\section{Selected References}

Serbesoff-King, K. 2003. Melaleuca in Florida: A literature review on the taxonomy, distribution, biology, ecology, economic importance and control measures. Journal of Aquatic Plant Management 41: 98-112.

Pratt, P. D., D. H. Slone, M. B. Rayamajhi, T. K. Van and T. D. Center. 2003. Geographic distribution and dispersal rate of Oxyops vitiosa (Coleoptera: Curculionidae), a biological control agents of the invasive tree Melaleuca quinquenervia in South Florida. Environmental Entomology 32: 396-406.

Center, T. D., T. K. Van, M. Rayachhetry, G. R. Buckingham, F. A Dray, S. Wineriter, M. F. Purcell and P. D. Pratt. 2000. Field colonization of the melaleuca snout beetle (Oxyops vitiosa) in south Florida. Biological Control 19: 112-123. 